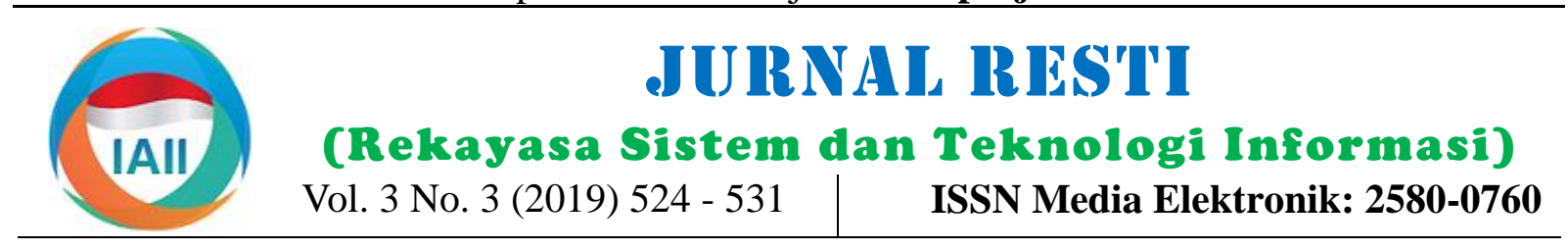

\title{
Implementasi Keras Library dan Convolutional Neural Network Pada Konversi Formulir Pendaftaran Siswa
}

\author{
Wahyu Andi Saputra ${ }^{1}$, Muhammad Zidny Naf'an ${ }^{2}$, Asyhar Nurrochman ${ }^{3}$ \\ ${ }^{123}$ Program Studi Informatika, Institut Teknologi Telkom Purwokerto \\ ${ }^{1}$ andi@ittelkom-pwt.ac.id, ${ }^{2}$ zidny@ittelkom-pwt.ac.id, ${ }^{3}$ azhar_rockman@yahoo.com
}

\begin{abstract}
Form sheet is an instrument to collect someone's information and in most cases it is used in a registration or submission process. The challenge being faced by physical form sheet (e.g. paper) is how to convert its content into digital form. As a part of study of computer vision, Optical Character Recognition (OCR) recently utilized to identify hand-written character by learning pattern characteristics of an object. In this research, OCR is implemented to facilitate the conversion of paper-based form sheet's content to be stored properly into digital storage. In order to recognize the character's pattern, this research develops training and testing method in a Convolutional Neural Network (CNN) environment. There are 262.924 images of hand-written character sample and 29 paper-based form sheets from SDN 01 Gumilir Cilacap that implemented in this research. The form sheets also contain various sample of human-based hand-written character. From the early experiment, this research results $92 \%$ of accuracy and $23 \%$ of loss. However, as the model is implemented to the real form sheets, it obtains average accuracy value of 63\%. It is caused by several factors that related to character's morphological feature. From the conducted research, it is expected that conversion of hand-written form sheets become effortless.
\end{abstract}

Keywords: optical character recognition, form-sheet conversion, keras library, convolutional neural network

\begin{abstract}
Abstrak
Lembar formulir merupakan salah satu media dalam mengumpulkan informasi seseorang dan umum digunakan pada proses registrasi/pendaftaran. Penggunaan media ini cukup mudah, namun hambatan yang kerap dihadapi dari penggunaan lembar formulir berbentuk fisik (misal: kertas) adalah pemindahan konten ke dalam bentuk digital. Optical Character Recognition (OCR) merupakan salah satu segmen dalam disiplin ilmu pengolahan citra yang dapat melakukan pengenalan karakter tulisan dengan mempelajari pola karakteristik suatu objek. Pada penelitian ini, OCR diimplementasikan pada keras library untuk memfasilitasi konversi konten tulisan tangan yang ada di sebuah kertas formulir sehingga dapat disimpan ke dalam media penyimpanan digital. Dalam pola pengenalan karakter, dikembangkan model pelatihan dan pengujian dengan menggunakan Convolutional Neural Network (CNN). Data yang digunakan pada penelitian adalah 262.924 karakter sampel tulisan tangan dalam bentuk citra dan 29 sampel kertas formulir dari SDN 01 Gumilir Cilacap. Model dengan akurasi tertinggi memperoleh nilai $92 \%$ dan loss sebesar 23\%. Sedangkan, pada hasil pengujian menggunakan 29 formulir didapatkan nilai akurasi rata-rata sebesar $63 \%$. Hal ini disebabkan oleh beberapa faktor yang berkaitan dengan faktor morfologi dari citra tiap karakter huruf. Dari penelitian yang dilakukan diharapkan dapat mempermudah proses dokumentasi informasi dari lembar formulir tulisan tangan ke dalam media penyimpanan digital.
\end{abstract}

Kata kunci: pengenalan karakter, konversi lembar formulir, keras library, convolutional neural network 


\section{Pendahuluan}

Sekolah adalah bangunan atau lembaga untuk belajar dan mengajar serta tempat menerima dan memberi pelajaran [1]. Di Indonesia, penjaringan calon peserta didik dilakukan melalui penerimaan siswa baru. Pada masa ini, sekolah berhak menyaring siapa saja siswa yang pantas untuk masuk di sekolah tersebut atau tidak. Dalam pelaksanaannya, salah satu tahapan pada proses pendaftaran siswa baru adalah pengisian biodata atau informasi diri menggunakan kertas formulir yang telah disediakan oleh pihak sekolah. Setelah itu, calon peserta didik mengisi formulir tersebut.

Data yang diperoleh dari situs Kementerian Pendidikan dan Budaya menyatakan bahwa terdapat 1.030 Sekolah Dasar (SD) yang ada di Kabupaten Cilacap; terdiri dari 976 berstatus negeri dan 54 berstatus swasta. Setelah ditelaah, informasi dari Dinas Pendidikan dan Kebudayaan Kabupaten Cilacap menyebutkan bahwa sekolah-sekolah tersebut masih menyelenggarakan sistem pendaftaran secara offline menggunakan lembar kertas formulir[2].

Pendaftaran menggunakan sistem offline memiliki tahap yang panjang dimana calon siswa akan diberikan lembar formulir, diisi dengan data diri, lalu mereka akan mengembalikan formulir ke pihak sekolah. Pihak sekolah kemudian akan merekap informasi yang ada di dalam formulir calon siswa ke dalam media penyimpanan digital (misal: database) secara manual satu-persatu sehingga membutuhkan waktu yang lama dan tidak efisien. Sayangnya, skema penginputan informasi secara konvensional ini masih diterapkan di sebagian besar sekolah yang ada di Indonesia. Secara tidak langsung, hal ini akan mempengaruhi kualitas layanan dari sekolah terkait seperti keterlambatan proses pendaftaran siswa baru [3].

Pada sekolah-sekolah yang terletak di kota dan memiliki akses internet, sistem pendaftaran dapat dilakukan dengan bantuan komputer. Ini disebabkan para orangtua di zaman modern telah fasih dalam menggunakan gawai dan piranti komputer terkini. Berbeda halnya dengan kondisi sekolah yang ada di dilakukan pendataan dengan menggunakan komputer karena para orang tua disana belum lancar dalam menggunakan media ini. Akibatnya, sekolah-sekolah di pinggiran masih menggunakan lembar kertas formulir dalam mendata identitas diri siswa meskipun hal ini tidak efektif dan tidak efisien [4].

Lambat dan tidak efisiennya metode penginputan informasi dari media kertas formulir menjadi latar belakang permasalahan. Tujuan dari penelitian ini adalah membangun sistem yang dapat mengkonversi informasi pada lembar kertas pendaftaran siswa baru ke dalam bentuk digital. Dengan mengimplementasikan Optical Character Recognition (OCR) untuk mengenali tulisan tangan pada lembar formulir, sistem akan dilatih untuk dapat merubah isi dari informasi ke dalam digital text. Setelah itu, informasi disimpan ke dalam database dengan format CSV guna memudahkan proses selanjutnya, baik itu dilakukan secara online maupun offline [5]. OCR mampu mengenali dan mengidentifikasi citra tulisan berupa huruf dan angka untuk dikonversikan ke dalam bentuk digital text[6].

Pada sistem yang dikembangkan, pendekatan image processing yang dilakukan (dengan masukan-keluaran berupa citra) adalah untuk melakukan manipulasi citra agar lebih mudah dikenali pada proses pelatihan dan pengujian. Adapun proses pada pengolahan citra yang memiliki peran paling besar pada penelitian ini adalah penentuan Region of Interest (RoI) dari citra hasil pemindaian. RoI akan melakukan pemilihan area yang kiranya memiliki pengaruh paling signifikan dalam mengenali karakter atau rangkaian teks dari hasil tulisan tangan pada formulir [7]-[9]. Lokasi dari tiap karakter terpencar-pencar sesuai dengan field yang ada pada formulir. Oleh sebab itu, menjadi tantangan tersendiri pada proses RoI untuk menentukan area of interest pada formulir yang akan dilakukan konversi.

Dalam penelitian ini, metode deep learning Convolutional Neural Network (CNN) digunakan untuk melakukan klasifikasi dari model yang dilatih. CNN merupakan variasi dari Multilayer Perceptron yang memiliki cara kerja seperti jaringan syaraf manusia, dapat beroperasi pada data dua dimensi, dan bagian dari Deep Neural Network karena kedalaman jaringan yang tinggi dan banyak diaplikasikan pada data citra khususnya pada kasus klasifikasi citra [10]-[12]. Algoritme CNN dapat mengenali karakter baru yang sebelumnya tidak ada dalam dataset dan dapat melakukannya dengan lebih ringkas karena di dalam CNN itu sendiri sudah terkandung Feature Extraction Layer [13]. Dalam penelitian ini, juga digunakan keras library pada python environment agar CNN dapat dijalankan dengan tepat dan lebih ringkas. Secara umum, dari penelitian ini, diharapkan dapat memberikan pengetahuan baru mengenai penerapan OCR dan CNN dalam melakukan konversi informasi dari lembar kertas formulir ke dalam bentuk digital.

\section{Metode Penelitian}

\subsection{Analisis dan Observasi}

Observasi dilakukan melalui wawancara kepada para guru di SDN 01 Gumilir Cilacap untuk menanyakan alur pendaftaran dan permasalahan yang dihadapi dalam proses pendaftaran calon siswa baru. Permasalahan yang didapat adalah sistem pendaftaran calon siswa yang dilakukan secara manual atau tulis tangan; tanpa menggunakan media komputer, sehingga pihak sekolah memasukan data calon siswa dengan mengetik ulang isi formulir satu demi satu. Hal ini dirasa tidak efisien dan memakan waktu. 


\subsection{Pengumpulan Data}

Sampel tulisan tangan didapat dari dataset pada kaggle.com [14] sebanyak 262.924 karakter sebagai dataset pelatihan. Dataset yang digunakan pada pengujian merupakan formulir pendaftaran siswa baru di SDN 01 Gumilir Cilacap sebanyak 29 sampel kertas formulir.

\subsection{Pembuatan Sistem dan Penerapan Metode CNN}

Sistem difasilitasi dengan Python 3. Dalam pengoperasiannya, sistem terdiri dari 2 alur operasi, yaitu operasi yang dilakukan secara offline dan operasi yang dilakukan secara online. Pada offline, operasi yang dilakukan adalah pembuatan model dan pelatihan dataset menggunakan CNN. Sedangkan, pada aktivitas online yaitu pembuatan konversi formulir yang akan digunakan untuk pengenalan karakter tulisan tangan pada formulir. Sistem konversi akan menjalankan beberapa tahapan proses untuk mengambil informasi yang dibutuhkan dari formulir, kemudian diterjemahkan dalam sebuah teks digital serta akan dimasukkan ke dalam format CSV. Gambar 1 Contoh perhitungan Sequence Matcher dapat dilihat menunjukkan gambaran sistem secara keseluruhan. pada ilustrasi berikut: Gambar 2 menunjukkan tahapan prapengolahan.

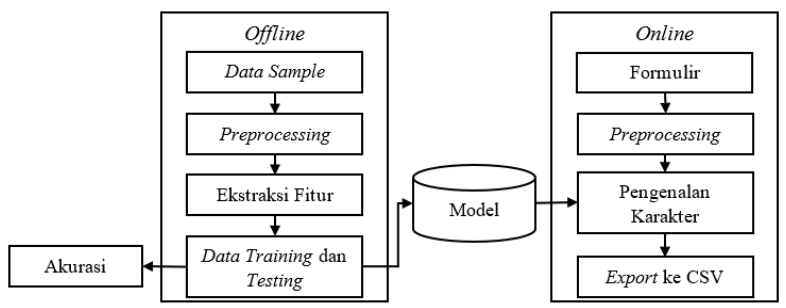

Gambar 1. Diagram dari sistem yang dikembangkan

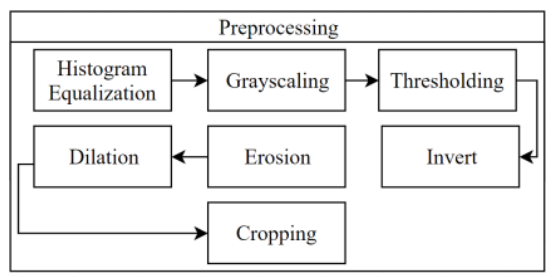

Gambar 2. Tahapan Preprocessing

Dalam pembuatan model, dilakukan 3 kali percobaan dengan perbandingan pelatihan dan pengujian data yang beragam. Tabel 1 menunjukkan komposisi perbandingan pada penelitian ini.

Untuk menguji sistem, pada penelitian ini dibangun sebuah website berbasis Flask-Python agar lebih mudah dalam pengoperasiannya. Dalam website yang dibangun, kumpulan citra diunggah untuk dilakukan proses komputasi agar diketahui nilai akurasi pada pengenalan karakternya. Pengujian dilakukan sebanyak 1 kali yaitu pada 29 citra formulir yang telah berisi tulisan tangan.
Tabel 1. Perbandingan Data Training dan Testing

\begin{tabular}{ccc}
\hline Percobaan & Pelatihan & Pengujian \\
\hline 1 & $60 \%$ & $40 \%$ \\
2 & $70 \%$ & $30 \%$ \\
3 & $80 \%$ & $20 \%$ \\
\hline
\end{tabular}

2.4. Perhitungan Nilai Akurasi dengan Sequence Matcher

Sequence Matcher merupakan salah satu metode untuk mengetahui tingkat kemiripan antar teks yang didasarkan pada algoritma Ratcliff/Obershelp [15]. Secara sederhana, algoritma ini akan membandingkan antara banyaknya kata yang terdeteksi secara benar dengan jumlah kata yang dibandingkan secara keseluruhan.

$$
D_{r} o=\left(\begin{array}{lll}
2 & x & k_{m}
\end{array}\right) /\left(\left|S_{1}\right|+\left|S_{2}\right|\right)
$$

dengan $\mathrm{k}_{\mathrm{m}}$ adalah banyaknya huruf yang terdeteksi dengan benar dari kedua kata, $S_{1}$ adalah huruf asli yang seharusnya muncul dari kata, dan $S_{2}$ adalah huruf yang terdeteksi oleh sistem dari kata.

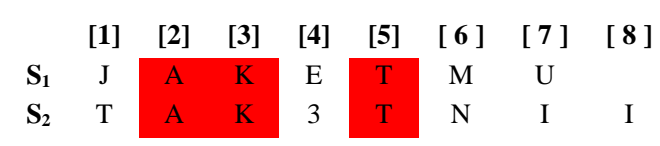

Dari bagan ilustrasi di atas, dapat diketahui:

1. Nilai $\mathrm{k}_{\mathrm{m}}$ adalah 3 , yaitu 3 huruf yang terdeteksi dengan benar dari kedua kata tersebut, yaitu A, $\mathrm{K}$, dan $\mathrm{T}$

2. Nilai $S_{1}$ adalah 7 , yaitu banyaknya huruf yang muncul pada kata yang seharusnya.

3. Nilai $\mathrm{S}_{2}$ adalah 8 , yaitu banyaknya huruf yang muncul dari hasil pendeteksian sistem.

sehingga, dari ilustrasi tersebut didapatkan nilai akurasi sebesar:

$$
\mathrm{D}_{\mathrm{r}} \mathrm{O}=(2 \times 3) /(|7|+|8|)=6 / 15=0,4
$$

\section{Hasil dan Pembahasan}

\subsection{Pembuatan Model secara offline}

Dalam pembuatan model, dataset diambil dari kaggle.com dan beberapa sampel tulisan tangan dari mahasiswa. Dataset ini berbentuk kumpulan citra dengan format .png yang berjumlah kurang lebih 5000 citra berdimensi $128 \times 128$ piksel pada tiap karakter. Dataset tersebut akan dilakukan beberapa tahap untuk dijadikan model pada sistem konversi seperti prapengolahan dan pelatihan menggunakan CNN.

\subsubsection{Preprocessing pada dataset}

Pada tahapan prapengolahan, dataset akan dilakukan operasi keabuan untuk dapat dilanjutkan operasi thresholding. Dalam operasi thresholding dan invers, keabuan yang awalnya putih dan objek yang awalnya 
hitam dibalik menjadi background hitam dan objek 3.1.2 Training dan Testing Data dengan CNN putih seperti pada Gambar 3.

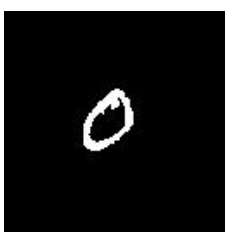

Gambar 3. Citra hasil thresholding

Operasi berikutnya adalah melakukan dilasi, dimana pada operasi ini objek akan terlihat lebih jelas dan tegas seperti ditunjukkan pada Gambar 4. Operasi dilasi dilakukan dengan menggunakan nilai kernel $(2,2)$ dimana objek akan semakin tebal sebesar 2 piksel.

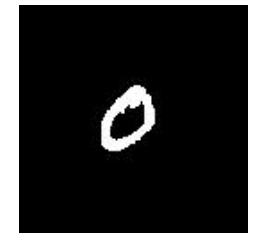

Gambar 4. Citra hasil dilasi

Setelah dilakukan dilasi, proses akan menjalankan pencarian Region of Interest (ROI) untuk mencari area utama pada citra. Hal ini ditunjukkan dengan Gambar 5. Setelah mendapatkan ROI pada citra, selanjutnya area tersebut dilakukan cropping untuk mendapatkan objek yang dibutuhkan (Gambar 5 dan Gambar 6).

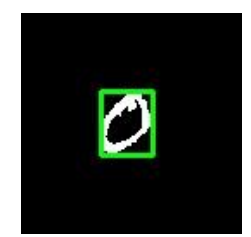

Gambar 5. ROI pada citra

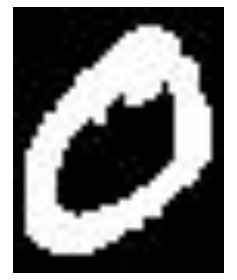

Gambar 6. Hasil cropping dari ROI

Tahap terakhir yaitu melakukan operasi resize untuk mengubah ukuran ROI dari 128x128 menuju 28x28 piksel. Pemilihan $28 \times 28$ piksel ini untuk mempercepat waktu pelatihan karena dimensi yang lebih kecil namun masih memiliki detail yang baik pada citra tersebut. Gambar 7 menunjukkan hasil resizing dari ROI.

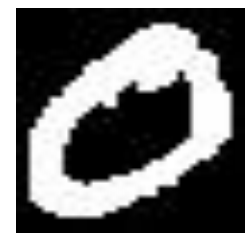

Gambar 7. Hasil resizing dari ROI
Dataset yang telah dilakukan prapengolahan berjumlah 262.924 citra, selanjutnya dataset tersebut dilakukan pelatihan dan pengujian untuk dijadikan model prediksi dan mendapatkan nilai akurasi awal. Pada proses training dan testing dilakukan 3 kali percobaan dengan komposisi berbeda. Secara umum, proses pelatihan dan pengujian dilakukan dengan skema Gambar 8 .

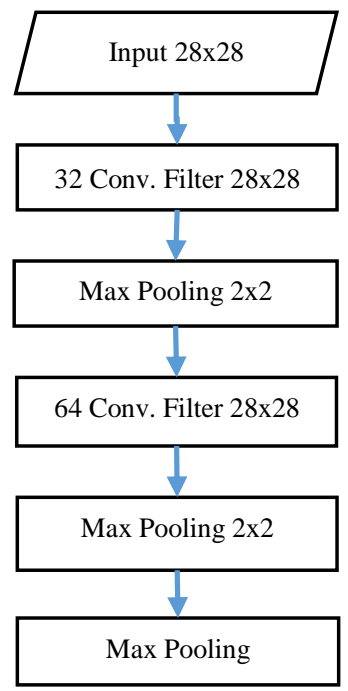

Gambar 8. Arsitektur CNN pada penelitian

Untuk melakukan pelatihan dengan metode CNN, penelitian ini difasilitasi dengan Google Colab yang dapat mengeksekusi program dengan Bahasa pemrograman python seperti jupyter notebook. Selain itu, Google Colab juga dapat mengeksekusi program dengan lebih cepat. Adapun spesifikasi CNN dari proses komputasi yang dilakukan adalah 1 layer input, 2 hidden layer, dan 1 output layer. Hasil pembuatan model disajikan pada Tabel 2.

Tabel 2. Hasil Pembuatan Model pada Data Training dan Testing

\begin{tabular}{ccccc}
\hline Percobaan & Pelatihan & Pengujian & Akurasi & Loss \\
\hline 1 & $60 \%$ & $40 \%$ & $91 \%$ & $24 \%$ \\
2 & $70 \%$ & $30 \%$ & $92 \%$ & $23 \%$ \\
3 & $80 \%$ & $20 \%$ & $91 \%$ & $24 \%$ \\
\hline
\end{tabular}

Dari ketiga percobaan pada Tabel 2, percobaan yang memiliki akurasi tertinggi dan loss terendah adalah percobaan kedua, yaitu dengan jumlah data training $70 \%$ dan data testing $30 \%$. Oleh karena itu, pada penelitian ini digunakanlah komposisi model kedua.

3.2 OCR untuk mengkonversi lembar formulir ke dalam digital teks secara online

\subsubsection{Prapengolahan - Pemisahan Antar Kata}

Library OpenCV digunakan dalam melakukan tahapan prapengolahan. Setelah itu, dilakukan bulk processing agar operasinya dapat dijalankan secara simultan. Untuk mendapatkan objek atau karakter yang diperlukan, dilakukan cropping secara manual dengan 
menentukan koordinat pada masing-masing objek seperti Gambar 9.

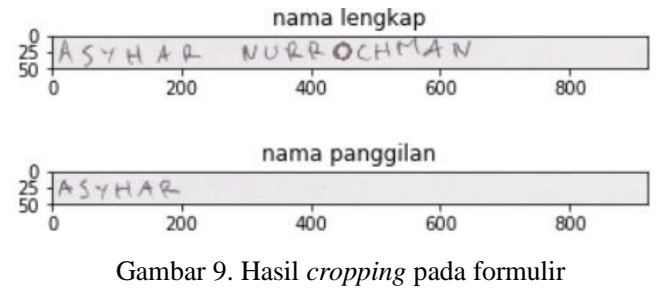

Objek tersebut kemudian dilakukan operasi grayscale dan thresholding. Operasi ini akan menghasilkan citra berskala keabuan dan biner yang akan membagi nilai derajat keabuan pada setiap piksel citra dalam 2 kelas, yaitu 0 (hitam) dan 1 (putih). Hasil dari proses ini ditunjukkan pada Gambar 10.
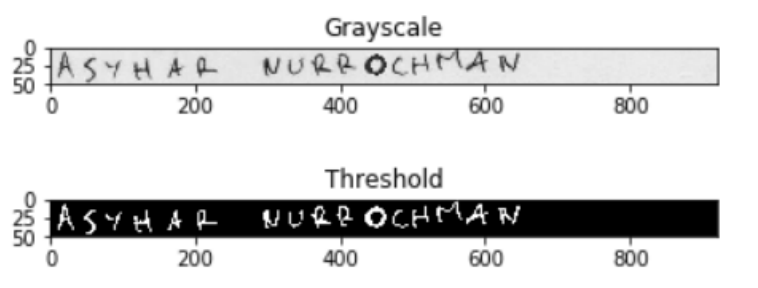

Gambar 10. Hasil dari Grayscale dan Thresholding

Untuk mengatasi derau, dilakukan operasi morfologi erosi di mana proses ini akan menipiskan atau mengecilkan objek derau. Nilai erosi yang digunakan adalah kernel $(2,2)$ dimana nilai kernel ini akan mengeliminasi 2 piksel pada sisi objek terhadap sumbu $\mathrm{x}$ dan $\mathrm{y}$. Imbasnya, selain menghilangkan derau, operasi ini juga dapat memperkecil citra aslinya.

Untuk mengatasi masalah ukuran citra yang berkurang, dilakukan proses dilasi yaitu menebalkan objek pada citra dengan menambahkan piksel pada objek sesuai nilai piksel yang diberikan. Untuk proses dilasi dilakukan 2 tahap, dimana untuk tahap pertama menggunakan nilai kernel $(5,25)$, yakni 5 piksel pada sumbu y dan 25 piksel pada sumbu $\mathrm{x}$. Hal ini berfungsi untuk menggabungkan tiap karakter pada setiap kata (Gambar 11) sehingga proses ROI yang dilakukan dapat memisahkan antarkata dengan lebih sempurna.

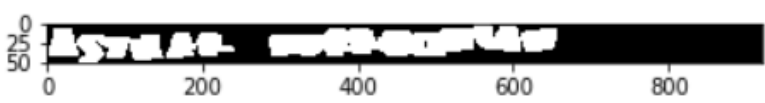

Gambar 11. Hasil dari dilasi tahap pertama

Proses selanjutnya yaitu pendeteksian ROI untuk memisahkan objek yang akan diolah dengan latar citra. Proses ini dilakukan sesuai dengan skema pada 3.1.1. Ketika ROI telah terdeteksi, proses akan dilanjutkan dengan cropping pada citra hasil thresholding. Untuk menghindari derau ikut terdeteksi maka dilakukan proses erosi agar derau bisa hilang atau tidak terdeteksi. Proses bounding box dan cropping tiap objek ditunjukkan pada Gambar 12 dan Gambar 13.
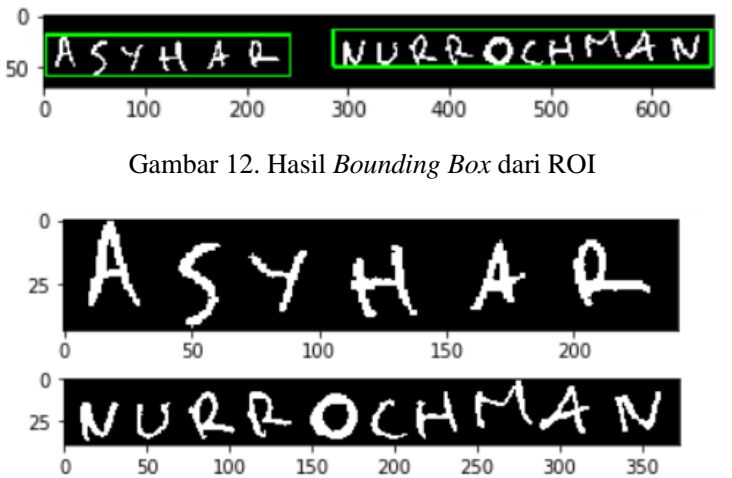

Gambar 13. Hasil cropping dari Bounding Box

Citra pada Gambar 16 nantinya akan dilakukan dilasi kembali namun dengan nilai kernel $(2,2)$; yakni 2 piksel pada sumbu y dan 2 piksel pada sumbu x. Hal ini bertujuan untuk menyambungkan karakter yang tidak terhubung seperti huruf "i" dan " $\mathrm{j}$ " agar terdeteksi sebagai sebuah karakter yang utuh.

\subsubsection{Preprocessing - Pemisahan Antar Karakter}

Dalam memisahkan antar karakter pada kata, dilakukan proses pendeteksian ROI dan cropping yang sama dari tahap sebelumnya, namun digunakan fungsi if $w<40$ and $h>15$ dimana objek yang memiliki lebar kurang dari 40 piksel dan tinggi lebih dari 15 piksel akan diseleksi (Gambar 14). Fungsi ini digunakan untuk membuang objek yang tidak dibutuhkan seperti pilihan pada jenis kelamin, warga negara, tempat tinggal dan lainya pada formulir.
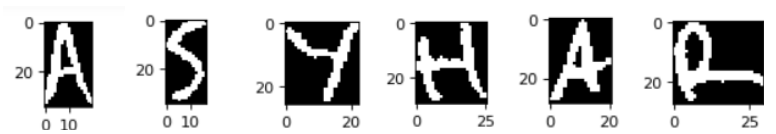

Gambar 14. Hasil cropping tanpa pelabelan

\subsubsection{Pengenalan Karakter}

Pada tahap pengenalan karakter, citra yang telah dilakukan cropping akan dilakukan proses deteksi dan prediksi karakter sesuai dengan dataset pada proses pelatihan. Untuk mendeteksi karakter ini digunakan model Hierarchial Data Format 5 (.hdf5) dimana model ini akan mendeteksi citra karakter satu persatu berdasarkan probabilitas yang muncul dari klasifikasi pada pembuatan model sebelumnya [16], [17]. Contoh hasil dari deteksi dapat dilihat pada Gambar 15 yang kemudian hasil dari pengenalan karakter disimpan dalam format CSV untuk memudahkan dalam pengolahan pada proses selanjutnya.
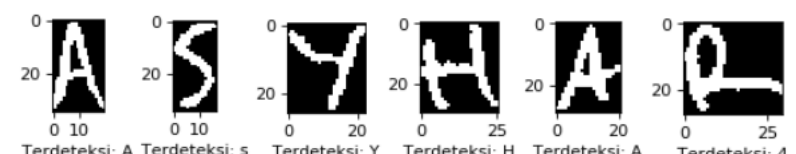

Gambar 15. Hasil Cropping dengan pelabelan 


\subsection{Implementasi Sistem}

Pada tahap ini, model yang telah ditentukan dan sistem yang telah dirancang akan diimplementasikan ke dalam bentuk situs aplikasi. Dalam pembuatan aplikasi berbasis web, digunakan bahasa pemrograman python dengan bantuan Microframework Flask. Fitur yang dibuat dalam sistem ini adalah mengkonversikan formulir yang telah dipindai selanjutnya informasi yang dibutuhkan pada formulir akan disimpan dalam bentuk CSV dan akan ditampilkan pada halaman hasil. Gambar 16 menunjukkan usecase pada pengembangan website.

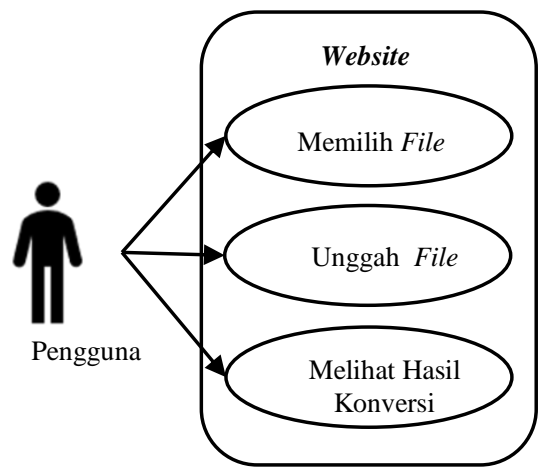

Gambar 16. Usecase Website

Gambar 16 menunjukkan sistem ini melibatkan satu aktor yaitu user, dimana user dapat memilih file zip yang akan dikonversi, kemudian user dapat mengupload file, dan selanjutnya user dapat melihat hasil dari sistem konversi formulir yang isinya berupa informasi dari seluruh formulir yang sudah diunggah.

Untuk menggunakan website ini, file formulir dimasukkan ke dalam satu folder yang kemudian dikompres ke dalam bentuk ZIP. Untuk mengunggah file, user dapat menekan tombol "Pilih File" untuk memilih file ZIP yang telah dikompres tadi. Lalu, file akan diunggah dan diproses. Halaman awal dari website dapat dilihat pada Gambar 17.

Setelah melakukan penggunggahan file ZIP, sistem akan menampilkan tombol "Konversi" untuk menjalankan proses konversi. Hasil konversi akan ditampilkan di layar seperti Gambar 18. Output akan tersimpan dalam bentuk CSV.

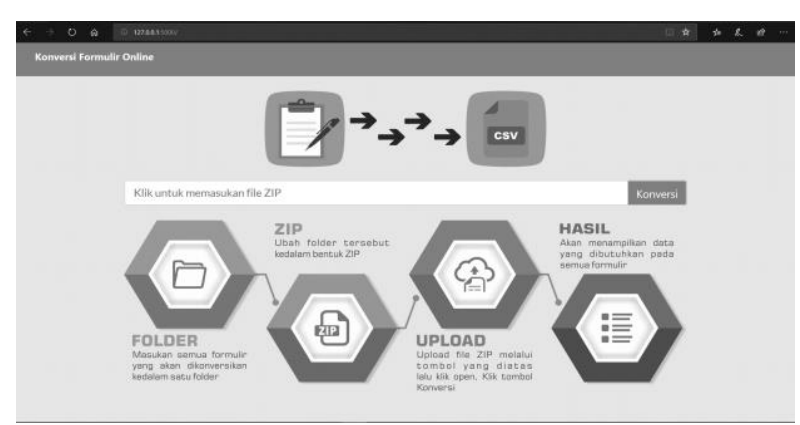

Gambar 17. Halaman awal pada website

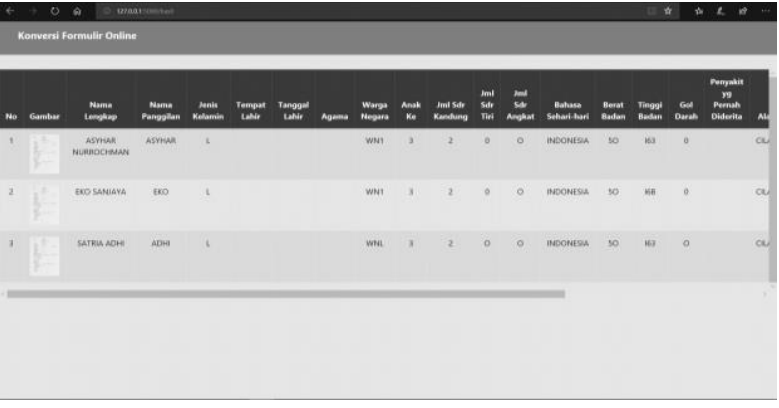

Gambar 18. Halaman hasil konversi pada website

\subsection{Pengujian dan Evaluasi}

Pada pengujian pertama, digunakan 10 lembar formulir percobaan yang dibuat sendiri dengan isi data fiktif sebagai dummy content. Kemudian, dilakukan proses konversi ke dalam digital guna mengetahui akurasi dari hasil percobaan; apakah hasil dari konversi sesuai dengan isi dari data pada formulir. Hasil dari percobaan dapat dilihat pada Tabel 2.

Nilai akurasi didapat dari perbandingan antara jumlah karakter (huruf) yang berhasil dideteksi benar dengan banyaknya karakter yang ada pada satu kata. Misalkan, pada kata "SISWA" banyaknya huruf yang terkandung di dalamnya adalah 5 huruf yang terdiri dari S, I, S, W, A. Tingkat akurasi akan bernilai $100 \%$ jika kelima huruf tersebut dapat dideteksi dengan benar oleh sistem. Namun, tingkat akurasi akan berkurang jika setidaknya salah satu huruf tidak terdeteksi dengan benar. Misalkan, dari kata "SISWA" ternyata terdeteksi sebagai "SISW4", maka nilai akurasi adalah 80\%. Nilai ini didapat dari 4 huruf yang terdeteksi dengan benar dibandingkan dengan 5 huruf yang ada pada kata tersebut.

Tabel 2. Contoh hasil konversi pada salah satu formulir dummy content

\begin{tabular}{|c|c|c|c|}
\hline $\begin{array}{c}\text { Baris } \\
\text { ke- }\end{array}$ & Output Sistem & $\begin{array}{l}\text { Kata yang } \\
\text { Seharusnya }\end{array}$ & Akurasi \\
\hline \multirow{3}{*}{1} & SYJFA REHITQ & SYIFA RENITA & \multirow{3}{*}{$78 \%$} \\
\hline & AYU & AYU & \\
\hline & RAN1I2DHANI & RAMADHANI & \\
\hline 2 & SY1FA & SYIFA & $80 \%$ \\
\hline 3 & PEPENIDUAH & PEREMPUAN & $53 \%$ \\
\hline \multirow{2}{*}{4} & C1LOCQP 20 & CILACAP 30 & \multirow{2}{*}{$52 \%$} \\
\hline & AUUSEUC ZOO9 & AGUSTUS 2009 & \\
\hline 5 & J5LAM & ISLAM & $60 \%$ \\
\hline 6 & WNI1 & WNI & $86 \%$ \\
\hline 7 & 2 & 2 & $100 \%$ \\
\hline 8 & \multirow[t]{3}{*}{2} & \multirow[t]{3}{*}{2} & $100 \%$ \\
\hline 9 & & & $100 \%$ \\
\hline 10 & & & $100 \%$ \\
\hline 11 & IMUCNE575Z & INDONESIA & $32 \%$ \\
\hline 12 & \multirow[t]{4}{*}{ 3SE42 } & \multirow[t]{4}{*}{$35 \mathrm{Kg}$} & $20 \%$ \\
\hline 13 & & & $100 \%$ \\
\hline 14 & & & $100 \%$ \\
\hline 15 & & & $100 \%$ \\
\hline \multirow{3}{*}{16} & SL DARUMA & JL BARUNA & \multirow{3}{*}{$69 \%$} \\
\hline & TIMUA SATU & TIMUR SATU & \\
\hline & OeI286497SZ & 08128644782 & \\
\hline & OT2RgTU2IMCr & Orang tua/ & \\
\hline 17 & $\begin{array}{l}\text { UMP2AgIUCM24 } \\
\text { D }\end{array}$ & $\begin{array}{l}\text { menumpang/ } \\
\text { asrama }\end{array}$ & $45 \%$ \\
\hline
\end{tabular}

Jurnal RESTI (Rekayasa Sistem dan Teknologi Informasi) Vol . 3 No. 3 (2019) 524 - 531 


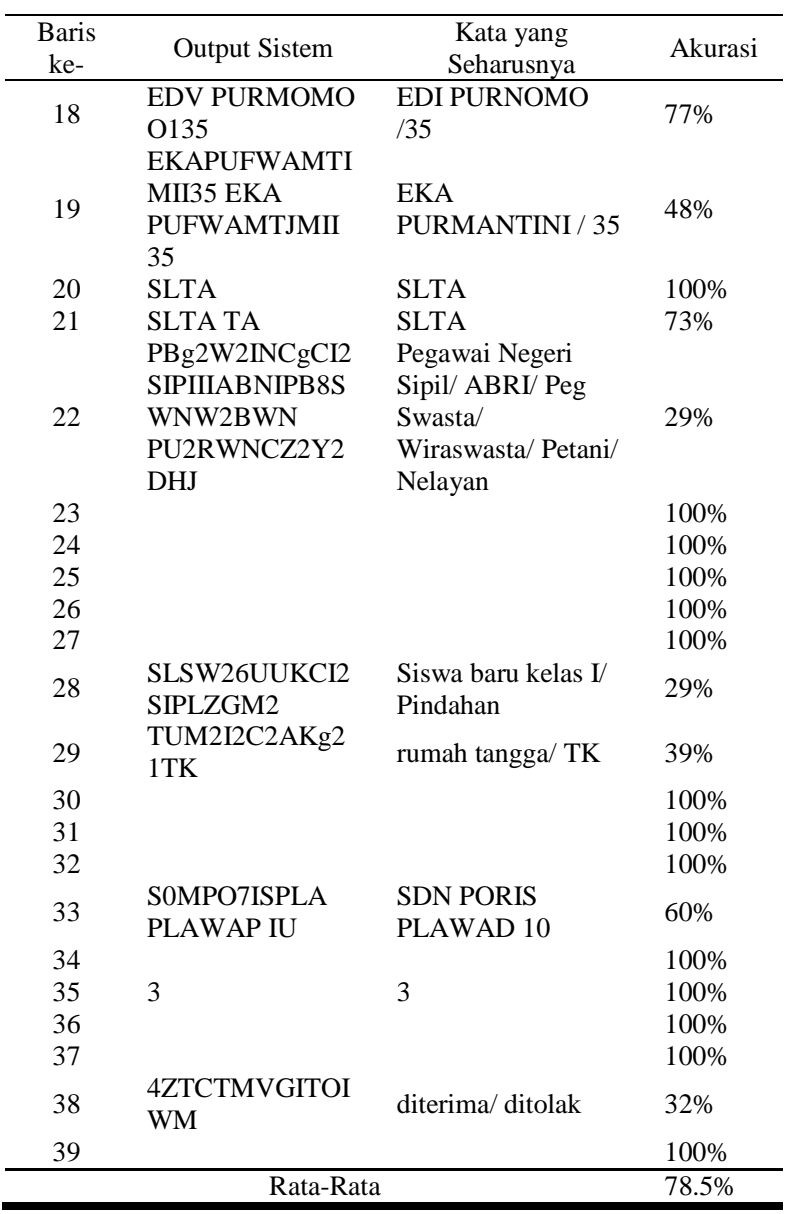

Terdapat perbedaan satu karakter yang mirip yaitu 1 (satu) dan I (huruf kapital i) sehingga sistem kesulitan Lebih lanjut, akurasi terendah didapatkan pada formulir untuk menerjemahkannya dengan tepat. Dari sini, 15 dengan tingkat akurasi 39,13\%. Hal ini disebabkan didapatkan nilai akurasi sebesar $80 \%$, yakni 4 dari total oleh karakter dari tulisan tangan yang saling 5 karakter yang benar. Meskipun sama-sama terdapat 5 berhimpitan sehingga sistem membacanya sebagai karakter yang terbaca, namun nilai akurasi didasarkan noise atau derau. Sebagaimana didukung oleh pada karakter yang terbaca dengan benar, bukan hanya penelitian dari [18], kelemahan CNN hingga kini sebatas terbaca. Contoh lain, baris 9 dan 10 merupakan adalah sulitnya mengenali karakter tulisan tangan yang contoh yang menunjukkan baris kosong yang tidak saling berhimpitan. Penggunaan operasi pada mengandung karakter.

Untuk pengujian data utama digunakan 29 sampel formulir lembar pendaftaran siswa yang didapat dari SDN 01 Gumilir Cilacap yang telah diisi oleh orang tua calon siswa. Sampel tersebut kemudian dilakukan konversi dan didapatkan hasil akurasi yang disajikan pada Tabel 3 .

Tabel 3. Hasil pengujian pada seluruh formulir

\begin{tabular}{lccc}
\hline Form ke & $\begin{array}{c}\text { Jumlah } \\
\text { Karakter yg } \\
\text { Dikenali }\end{array}$ & $\begin{array}{c}\text { Jumlah } \\
\text { Karakter } \\
\text { Sebenarnya }\end{array}$ & Akurasi \\
\hline Form 1 & 272 & 357 & $59.26 \%$ \\
Form 2 & 240 & 318 & $56.03 \%$ \\
Form 3 & 347 & 338 & $78.50 \%$ \\
Form 4 & 396 & 384 & $59.43 \%$ \\
Form 5 & 346 & 432 & $58.28 \%$ \\
Form 6 & 198 & 261 & $71.90 \%$ \\
Form 7 & 167 & 210 & $61.04 \%$ \\
Form 8 & 226 & 265 & $68.08 \%$
\end{tabular}
pengolahan citra, yakni erosi dan dilasi sangat berpengaruh dalam memisahkan maupun menggabungkan antarkarakter agar terbaca oleh sistem. Operasi ini memiliki dampak yang signifikan karena secara langsung mempengaruhi morfologi dari citra. Selain alasan tersebut, formulir 15 masih mengandung huruf non-kapital dimana pada model CNN yang dilatih nilai akurasi pada huruf kecil memiliki akurasi yang minim.

\section{Kesimpulan}

\subsection{Kesimpulan}

Kombinasi antara Keras Library dan CNN dapat digunakan untuk mengkonversi lembar formulir pendaftaran siswa yang berisi tulisan tangan ke dalam bentuk teks digital. Beberapa operasi pengolahan citra yang dilakukan agar karakter dapat terbaca oleh sistem adalah konversi grayscale, thresholding, erosi, dilasi, 
ROI detection, cropping, dan resize. Dari penelitian ini, digunakan model pengklasifikasian CNN dengan nilai akurasi sebesar 92\%. Namun, setelah diterapkan secara riil, didapatkan nilai akurasi sebesar $63 \%$. Beberapa faktor yang mempengaruhi keakuratan sistem dalam mengenali teks adalah karakter yang saling berhimpitan, tingkat kemiringan karakter, jenis kapital karakter, dan operasi pada praprocessing yang belum sempurna.

\subsection{Saran}

Diharapkan pada penelitian selanjutnya dapat meningkatkan akurasi sistem dalam mengkonversi lembar formulir dari tulisan tangan ke dalam bentuk teks digital. Saran untuk pengembangan sistem kedepannya adalah:

1. Memperbanyak jumlah dataset serta varian karakter sehingga dapat memperkaya mesin komputasi dalam mempelajari ciri khas tiap karakter.

2. Menambah variasi praprocessing yang dilakukan sehingga dapat memisahkan antar karakter dengan lebih sempurna seperti penggunaan ekstrasi fitur yang khusus ditujukan pada kasus pengenalan huruf.

3. Membuat formulir khusus dengan garis bantuan berbentuk kotak-kotak agar lebih mudah dalam memisahkan antarkarakter.

\section{Daftar Rujukan}

[1] Tim Pusat Bahasa Departemen Pendidikan Nasional, Kamus Bahasa Indonesia, Edisi XVI. Jakarta: Pusat Bahasa, 2008.

[2] Direktorat Jenderal Pendidikan Dasar dan Menengah, 2018. Jumlah Data Satuan Pendidikan (Sekolah) per Kabupaten/Kota: Kabupaten Cilacap. [Daring]. Tersedia http://referensi.data.kemdikbud.go.id/index21_t kra.php?kode $=026600 \&$ level $=2$.

[3] B. Warsita, 2015. Evaluasi Sistem Penerimaan Peserta Didik Baru (PPDB) Online untuk Peningkatan Kualitas Pembelajaran. Jurnal Kwangsan. 3 (1). hal. 27.

[4] S. Maulina, Respon Orang Tua Peserta Didik SMP atas Layanan Inormasi Penerimaan Peserta Didik Baru (PPDB) Melalui Media Online oleh Dinas Pendidikan Kota Malang, 2013.

[5] J. Sutresna, 2017. Perancangan Sistem Formulir Pelayanan Kedukaan Online Menggunakan Metode Web Base Engineering Pada Pt . Abadi Cahaya Universal ( Rumah Duka Abadi ) Jakarta. Jurnal Informatika Universitas Pamulang. 2 (2). hal. 108-113.

[6] S. Hartanto, A. Sugiharto, dan S. N. Endah, 2015.
Optical Character Recognition Menggunakan Algoritma Template Matching Correlation. Jurnal Masyarakat Informatika. 5 (9). hal. 1-12.

[7] R. F. Falah, O. D. Nurhayati, dan K. T. Martono, 2016. Aplikasi Pendeteksi Kualitas Daging Menggunakan Segmentasi Region of Interest Berbasis Mobile. Jurnal Teknologi dan Sistem Komputer. 4 (2). hal. 333-343.

[8] B. Al-Mahadeen, M. S. Altarawneh, dan I. H. Altarawneh, 2010. Signature Region of Interest using Auto cropping. IJCSI International Journal of Computer Science Issues. 7 (2). hal. 1-5.

[9] H. A. Nugroho, W. A. Saputra, A. E. Permanasari, dan E. E. H. Murhandarwati, 2017. Automated determination of plasmodium region of interest on thin blood smear images. 2017 International Seminar on Intelligent Technology and Its Application: Strengthening the Link Between University Research and Industry to Support ASEAN Energy Sector, ISITIA 2017 - Proceeding. 2017-Janua . hal. 352-355.

[10] M. Zufar dan B. Setiyono, 2016. Convolutional Neural Networks untuk Pengenalan Wajah Secara Real-Time. Jurnal Sains dan Seni. 5 (3). hal. 1-6.

[11] Sukardi, Z. Arifin, dan M. Risaldi, Klasifikasi Penentuan Gambar Berbasis Tensorform Dan Framework Dengan Algoritma CNN, in Seminar Nasional APTIKOM (SEMNASTIKOM), 2017, hal. 1-4.

[12] Y. Pramudana, 2015. Pengenalan Tulisan Tangan Dengan Menggunakan Metode Diagonal Feature Extraction dan K-Nearest Neighbour. Bandung.

[13] J. Pujoseno, Implementasi Deep Learning Menggunakan Convolutional Neural Network Untuk Klasifikasi Alat Tulis, Universitas Islam Indonesia, Yogyakarta, 2018.

[14] https://www.kaggle.com/tejasreddy/iam-handwritingtop50.

[15] S. A. J. Zaidi, A. Buriro, M. Riaz, A. Mahboob, dan M. N. Riaz, 2019. Implementation and comparison of textbased image retrieval schemes. International Journal of Advanced Computer Science and Applications. 10 (1). hal. 611-618.

[16] M. Jackson, J. P. Simmons, dan M. De Graef, 2010. MXA: A customizable HDF5-based data format for multi-dimensional data sets. Modelling and Simulation in Materials Science and Engineering. 18 (6).

[17] R. Bhowmik, J. Hartog, dan M. Govindaraju, 2013. Processing HDF5 datasets on multi-core architectures. Proceedings - International Conference on Advanced Information Networking and Applications, AINA. hal. 666-673.

[18] R. Wiles, 2019. Have we solved the problem of handwriting recognition? [Daring]. Tersedia di: https://towardsdatascience.com/https-medium-comrachelwiles-have-we-solved-the-problem-ofhandwriting-recognition-712e279f373b. [Diakses: 02Okt-2019]. 